\title{
A computational high-throughput search for new ternary superalloys
}

\author{
Chandramouli Nyshadham ${ }^{\mathrm{a}}$, Corey Oses ${ }^{\mathrm{b}}$, Jacob E. Hansen ${ }^{\mathrm{a}}$, Ichiro Takeuchi ${ }^{\mathrm{c}}$, Stefano Curtarolo ${ }^{\mathrm{b}, \mathrm{d}}$, Gus \\ L. W. Hart ${ }^{\mathrm{a}, *}$ \\ ${ }^{a}$ Department of Physics and Astronomy, Brigham Young University, Provo, Utah 84602, USA. \\ ${ }^{b}$ Center for Materials Genomics, Duke University, Durham, North Carolina 27708, USA. \\ ${ }^{c}$ Department of Materials Science and Engineering, University of Maryland, College Park, Maryland 20742, USA. \\ ${ }^{d}$ Department of Mechanical Engineering and Materials Science and Department of Physics, Duke University, Durham, \\ North Carolina 27708, USA.
}

\begin{abstract}
In 2006, a novel cobalt-based superalloy was discovered [1] with mechanical properties better than some conventional nickel-based superalloys. As with conventional superalloys, its high performance arises from the precipitate-hardening effect of a coherent $\mathrm{L}_{2}$ phase, which is in two-phase equilibrium with the fcc matrix. Inspired by this unexpected discovery of an $\mathrm{L}_{2}$ ternary phase, we performed a first-principles search through 2224 ternary metallic systems for analogous precipitate-hardening phases of the form $X_{3}\left[A_{0.5}, B_{0.5}\right]$, where $X=\mathrm{Ni}, \mathrm{Co}$, or $\mathrm{Fe}$, and $[A, B]=\mathrm{Li}, \mathrm{Be}, \mathrm{Mg}, \mathrm{Al}, \mathrm{Si}, \mathrm{Ca}, \mathrm{Sc}, \mathrm{Ti}, \mathrm{V}, \mathrm{Cr}, \mathrm{Mn}, \mathrm{Fe}, \mathrm{Co}, \mathrm{Ni}, \mathrm{Cu}, \mathrm{Zn} \mathrm{Ga}$, $\mathrm{Sr}, \mathrm{Y}, \mathrm{Zr}, \mathrm{Nb}, \mathrm{Mo}, \mathrm{Tc}, \mathrm{Ru}, \mathrm{Rh}, \mathrm{Pd}, \mathrm{Ag}, \mathrm{Cd}, \mathrm{In}, \mathrm{Sn}, \mathrm{Sb}, \mathrm{Hf}, \mathrm{Ta}, \mathrm{W}, \mathrm{Re}, \mathrm{Os}, \mathrm{Ir}, \mathrm{Pt}, \mathrm{Au}, \mathrm{Hg}$, or Tl. We found 102 systems that have a smaller decomposition energy and a lower formation enthalpy than the $\mathrm{Co}_{3}(\mathrm{Al}, \mathrm{W})$ superalloy. They have a stable two-phase equilibrium with the host matrix within the concentration range $0<x<1\left(X_{3}\left[A_{x}, B_{1-x}\right]\right)$ and have a relative lattice mismatch with the host matrix of less than or equal to 5\%. These new candidates, narrowed from 2224 systems, suggest possible experimental exploration for identifying new superalloys. Of these 102 systems, 37 are new; they have no reported phase diagrams in standard databases. Based on cost, experimental difficulty, and toxicity, we limit these 37 to a shorter list of six promising candidates of immediate interest. Our calculations are consistent with current experimental literature where data exists.
\end{abstract}

Keywords: First-principles calculations, Superalloys, High-throughput, Phase stability

\section{Introduction}

Materials scientists have developed large experimental databases of known materials over the last century $[2,3,4,5]$. Similar computational databases are being compiled by exploiting the power of supercomputers and advanced electronic structure methods $[6,7,8,9,10,11]$. The challenge now is to leverage the data to discover new materials by building computational models [12] and employing machine learning methods $[13,14,15,16]$. Data mining and materials informatics approaches can also be used to identify structure/property relationships, which may suggest atomic combinations, stoichiometries, and structures not included in the database [12].

\footnotetext{
${ }^{*}$ Corresponding author. Tel.: +1-801-422-7444

Email address: gus.hart@gmail.com (Gus L. W. Hart)
}

Preprint submitted to Acta Materialia
An emerging area in materials science is the computational prediction of new materials using highthroughput approaches $[6,12,13,14,17,18,19,20]$. Hundreds of thousands of hypothetical candidates can be explored much faster than by experimental means. In this work, a simple combinatorial search for ternary superalloys is performed in a high-throughput fashion. The extraordinary mechanical properties of superalloys at high temperatures make them useful for many important applications in the aerospace and power generation industries. One of the basic traits of superalloys is that they generally occur in a face-centered-cubic structure [21]. The most common base elements for superalloys are nickel, cobalt, and iron, but most are nickel-based. In 2006, a new cobalt-based superalloy, $\mathrm{Co}_{3}(\mathrm{Al}, \mathrm{W})$, was confirmed to have better mechanical properties than many nickel-based su- 
Figure 1: For each base element in $X_{3}\left[A_{0.5}, B_{0.5}\right]$, there are 40 elements chosen for $A$ and $B$, which includes 38 elements (highlighted in blue) chosen from the periodic table and the remaining two of three base elements $X$ (highlighted in red).

peralloys [1].

This cobalt-based superalloy has the commonly occurring $\mathrm{L}_{2}$ phase which creates coherent precipitates in the fcc matrix. A theoretical investigation of $\mathrm{Co}_{3}(\mathrm{Al}, \mathrm{W})$ was subsequently carried out by Saal and Wolverton [22]. To model the properties of the $\mathrm{L}_{2}$ solid solution phase observed at high temperature, Saal and Wolverton used an $\mathrm{L1}_{2^{-}}$ based special quasirandom structure (SQS) [23]. In order to identify the stoichiometry of the superalloy, they performed first-principles calculations for solid solutions $\mathrm{Co}_{3}\left[\mathrm{Al}_{x}, \mathrm{~W}_{1-x}\right]$ with varying concentrations of $\mathrm{Al}$ and $\mathrm{W}$. Their study includes finite temperature effects and point defect energetics. They showed that an $\mathrm{L}_{2}$-like random structure with stoichiometry $\mathrm{Co}_{3}\left[\mathrm{Al}_{0.5}, \mathrm{~W}_{0.5}\right]$ is consistent with experiment. Interestingly, their solid-solutionlike $\mathrm{Co}_{3}\left[\mathrm{Al}_{0.5}, \mathrm{~W}_{0.5}\right]$ structure is metastable and predicted to have a decomposition energy of 66 $\mathrm{meV} /$ atom (distance from the $T=0 \mathrm{~K}$ convex hull). They show that high-temperature effects make this phase thermodynamically competitive with other competing structures at elevated temperatures. The fact that a metastable structure $\left(\mathrm{Co}_{3}\left[\mathrm{Al}_{0.5}, \mathrm{~W}_{0.5}\right]\right)$ with a decomposition energy as high as $66 \mathrm{meV} /$ atom at $\mathrm{T}=0 \mathrm{~K}$, is competitive with many commercially available superalloys at higher temperatures motivates our search for similar ternary systems containing an $\mathrm{L}_{2}$-like solid solution phase.

Ideally, a computational search over potential superalloys would model actual engineering observables (e.g., hardness) and consider the influence of small concentrations of impurities, finite tempera- ture effects, influence of vacancies, effects of polycrystallinity, etc. Unfortunately, such calculations are extremely challenging even for a single material and impractical for thousands of candidate systems as in this work.

In known superalloy systems, $\mathrm{L} 1_{2}$-based phases have large negative formation enthalpies, a small decomposition energy, and a relatively small lattice mismatch between the host matrix and the precipitate phase. Our search is for new ternary systems with these same metrics. We further screen candidate alloy systems for $\mathrm{L}_{2}$ precipitates either in two-phase equilibrium with the host matrix or likely to precipitate as metastable phases. Based on the relative lattice mismatch between the host element and the precipitate phases any compound with a relative lattice mismatch of $>5 \%$ is excluded.

Using the solid-solution-like structure identified by Saal and Wolverton [22], we performed an extensive combinatorial search over 2224 ternary systems using the AfLOw framework [7, 8]. We found 102 systems that are more stable (closer to the $T=0 \mathrm{~K}$ convex hull) and have a lower formation enthalpy than the $\mathrm{Co}_{3}\left[\mathrm{Al}_{0.5}, \mathrm{~W}_{0.5}\right]$ superalloy. All 102 systems are in two-phase equilibrium with the host matrix and have a relative lattice mismatch of less than or equal to $5 \%$. Of these systems, 37 are new - they have no reported phase diagrams $[4,24,5]$. These new candidates, narrowed from thousands of possibilities, suggest experimental exploration for identifying new superalloys. Furthermore, by eliminating systems that are experimentally difficult to make or contain expensive or toxic elements, we identify six particularly promising systems. 


\section{Methodology}

\subsection{First-principles structure calculations}

We performed first principles calculations using the software package AfLOw [7]. To model an $\mathrm{L1}_{2}$-based solid solution, we used a 32 -atom special quasirandom structure (SQS-32) [23, 25, 22] of the form $X_{3}\left[A_{0.5}, B_{0.5}\right]$, where $X$ is one of the base elements, nickel $(\mathrm{Ni})$, cobalt $(\mathrm{Co})$ or iron $(\mathrm{Fe})$ (refer Fig. 1). These combinations lead to 780 different ternary structures for each base element totaling to 2340 SQS structures in 2224 different ternary systems.

All the calculations follow the AfLOw [26] standard, are hosted in the AFLOW repository [8], and can be easily accessed by using the RESTAPI [27]. Each ab-initio calculation is performed using PAW potentials $[28,29,30]$ within the generalized gradient approximation of Perdew, Burke, and Ernzerhof [31, 32], as implemented in VASP [33, 34]. The $k$-point meshes for sampling the Brillouin zone are constructed using the Monkhorst-Pack scheme [35]. A total number of at least $10,000 k$-points per reciprocal atom are used, and spin polarization [26] is considered. The cutoff energy is chosen to be 1.4 times the default maximum value of the three elements in the respective ternary system. More details are available in Ref. [26].

The special quasirandom structure (SQS) [23] approach mimics the statistics of a random alloy in a small supercell [36]. Fig. 2 depicts the 32-atom SQS [25] that was used for all calculations in this work. It is an $\mathrm{L1}_{2}$-based structure where $X$ atoms (blue) are on the face centers of the conventional fcc cell and $A$ (red), $B$ (green) atoms on the corners.

\subsection{Thermodynamic property calculations}

The formation enthalpy $\left(\Delta H_{f}\right)$ is calculated for any ternary structure $X_{3}\left[A_{0.5}, B_{0.5}\right]$ as

$$
\Delta H_{f}=E\left(X_{3}\left[A_{0.5}, B_{0.5}\right]\right)-\sum_{m} E_{m},
$$

where $E\left(X_{3}\left[A_{0.5}, B_{0.5}\right]\right)$ is the total energy per atom of the SQS- $32-X_{3}\left[A_{0.5}, B_{0.5}\right]$ structure, and $\sum_{m} E_{m}$ is the sum of total energies of the corresponding stable, pure concentration structures. A negative formation enthalpy characterizes a system that prefers an ordered configuration over decomposition into its pure constituents, while unstable systems have a positive formation enthalpy.

To approximate the phase diagram of a given alloy system, we consider the low-temperature limit

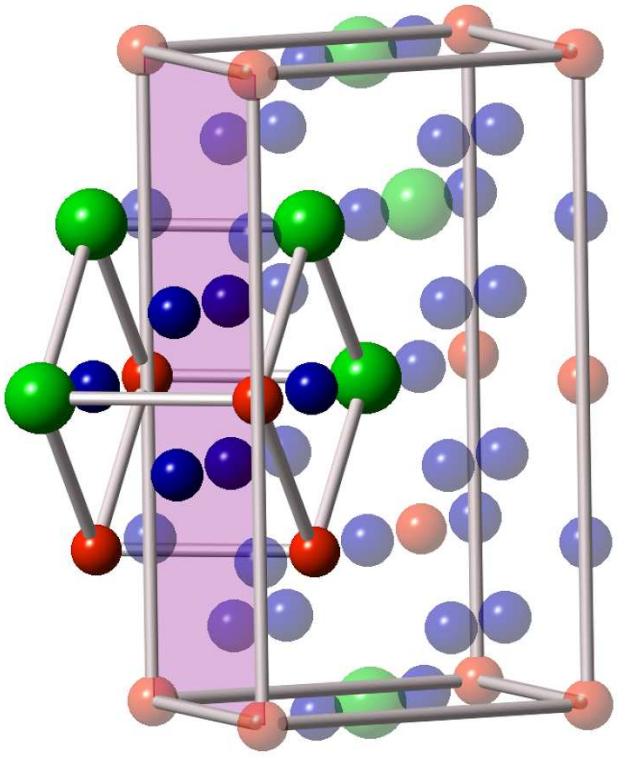

Figure 2: The 32-atom special quasirandom structure (SQS32) [25] used to model a solid solution with an $\mathrm{L}_{2}$ structure (smaller cube in the figure). The blue, red, and green atoms correspond to $X, A$, and $B$ in $X_{3}\left[A_{0.5}, B_{0.5}\right]$, respectively.

in which the behavior of the system is dictated by the ground state [37, 38]. In compositional space, the set of ground state configurations defines the minimum energy surface, also referred to as the lower-half convex hull. All compounds above the minimum energy surface are not stable, with the decomposition described by the hull member or facet directly below each. The energy gained from this decomposition is geometrically represented by the distance of the compound from the hull and quantifies the compound's tendency to decompose. We refer to this quantity as the decomposition energy.

While the minimum energy surface changes at finite temperature (favoring disordered structures), we expect the $T=0 \mathrm{~K}$ decomposition energy to serve as a reasonable descriptor for relative stability. The ternary convex hulls and relevant calculations were performed ${ }^{1}$ using the phase diagram

\footnotetext{
${ }^{1}$ We found in our calculations that the formation enthalpy of two compounds, namely $\mathrm{Al}_{2} \mathrm{Co}$ and $\mathrm{Al}_{2} \mathrm{Fe}$ with $\mathrm{Be}_{2} \mathrm{Zn}$ structure (the prototype numbered 549 in AfLOW [8]), is anomalously low $(<-1.8 \mathrm{eV} /$ atom). Similar results with this $\mathrm{Be}_{2} \mathrm{Zn}$ structure for other compounds were discussed previously by Taylor et al. [39]. They attribute the erroneous results to PAW-pseudopotentials distributed with VASP. The phase diagrams for systems with binary combinations (Al, $\mathrm{Co})$ or $(\mathrm{Al}, \mathrm{Fe})$ are generated discarding the $\mathrm{Be}_{2} \mathrm{Zn}$ structure in this work.
} 
module within Aflow [7] (see Appendix for details).

We observe that ternary $\mathrm{L}_{2}$ phases in known superalloys have large negative formation enthalpies and appear near each other in Pettifor-like maps of the formation enthalpy and decomposition energy. Decomposition energy and formation enthalpy maps comprising all 2224 systems considered in this study are shown in Figs. 5 and 6. All those systems for which decomposition energy and formation enthalpy are less than that of $\mathrm{Co}_{3}\left[\mathrm{Al}_{0.5}, \mathrm{~W}_{0.5}\right]$ are included in our list of potential candidates.

\subsection{Coherency and two-phase equilibrium with the host}

Because the strain energy cost is lower, compounds with smaller lattice mismatch between the $\mathrm{L}_{2}$ phase and the host matrix are more likely to form coherent precipitates. Relative lattice mismatch $\left(\Delta a / a_{\text {host }}\right)$ is defined as the ratio of the difference between the lattice parameter of the host matrix and the precipitate compound, $\Delta a$, to the lattice parameter of host matrix, $a_{\text {host }}$. In this work, a relative lattice mismatch cutoff of no more than $5 \%$ is used to screen for potential superalloys.

Because precipitate strengthening is the key mechanism for superalloy performance, we apply a second constraint requiring that the $\mathrm{L} 1_{2}$ precipitate phase be in two-phase equilibrium with the fcc host matrix. ${ }^{2}$ As shown in Fig. 3, this constraint is satisfied if a tie-line can be drawn between the host matrix $(100 \% X)$ and the $\mathrm{L}_{2}$ phase at any concentration $\left(X_{3}\left[A_{x}, B_{1-x}\right], 0<x<1\right)$ without intersecting any other tieline. We allow for this variation in the concentration for the minority site $\left(A_{x} B_{1-x}\right)$ because stable $\mathrm{L} 1_{2}$ phases in experiment can vary over a wide concentration range $[40,41]$. Of the 179 systems with deeper formation enthalpy and smaller decomposition energy than Co-Al-W, 66 systems are eliminated using the two-phase equilibrium criterion.

\subsection{Bulk modulus calculations}

The bulk modulus is determined from energyvolume data calculated for strains of $-0.02 \AA$ to $+0.02 \AA$ in steps of $0.01 \AA$ applied to the unit cell,

\footnotetext{
${ }^{2}$ In cases where the formation enthalpy of the SQS structure is above the convex hull, we project it onto the convex hull and draw the tieline between the projected point and the host matrix to check the two-phase equilibrium criterion.
}

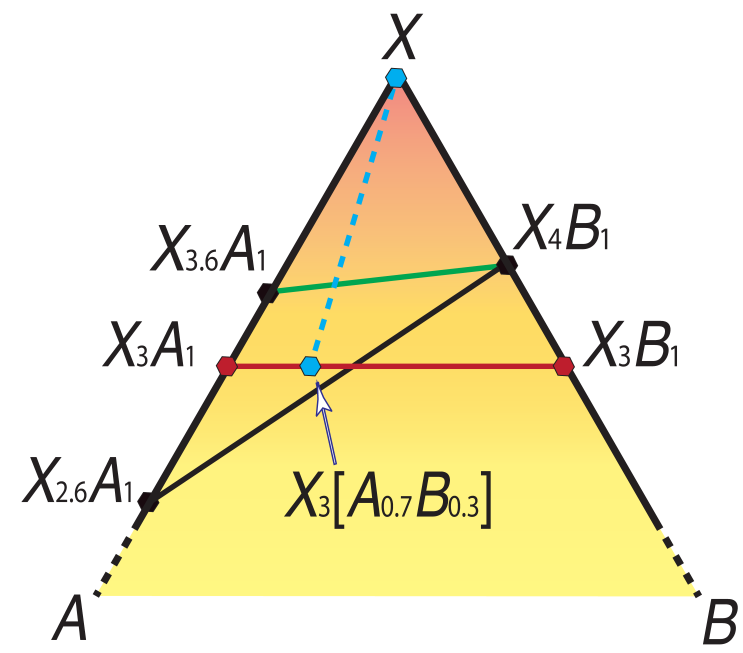

Figure 3: The two-phase equilibrium screening criterion discussed in Sec. 2.3 (similar to Fig. 2 in Ref. [42]). If a tieline between the host matrix and the $\mathrm{L} 1_{2}$ precipitate phase (light blue dotted line) is intersected by the tie line for another phase (e.g., green line between $X_{3.6} A_{1}$ and $X_{4} B_{1}$ ) then the precipitate phase will not be in two-phase equilibrium with the host matrix for any concentration between $X_{3} A_{1}$ and $X_{3} B_{1}$. On the other hand, even if the line connecting $X_{3} A_{1}$ and $X_{3} B_{1}$ is intersected by another tie line (e.g., black line between $X_{2.6} A_{1}$ and $X_{4} B_{1}$ ), there may still be a concentration of the precipitate phase that can be in two-phase equilibrium with the host matrix, as show by the light-blue dotted line.

with at least five calculations for each system. The energy-volume data is fitted using the Murnaghan equation of state [43].

\section{Results and analysis}

\subsection{Relative stability of $S Q S-32$ and the distance to convex hull}

Fig. 4 depicts the formation enthalpy $\left(\Delta H_{f}\right)$ vs. decomposition energy $\left(E_{d}\right)$ for all 2224 SQS-32 ternary systems with composition distinguished by color. It is found that $2111 / 2224$ ternary systems are compound-forming. Each point on the plot represents one $\mathrm{Ni}_{3} / \mathrm{Co}_{3} / \mathrm{Fe}_{3}(A, B)$ system, where $A$ and $B$ are any two different elements highlighted in Fig. 1. On average, Ni-based superalloys are thermodynamically more stable than Co- or Fe-based superalloys.

The SQS-32 structure in 179 ternary systems is found to be thermodynamically more stable and have lower formation enthalpy than the $\mathrm{Co}_{3}(\mathrm{Al}, \mathrm{W})$ 
system. These systems are enclosed within dotted lines in Fig. 4. Out of these systems, 152 are Nibased, 22 are Co-based, and 5 are Fe-based. Furthermore, 102 systems of these 179 are observed to be in two-phase equilibrium with the host matrix and have no more than $5 \%$ relative lattice mismatch with respect to the respective host lattice. Of these 102 systems, 37 have no reported phase diagrams in standard databases $[4,5,24]$. Of these systems, 33 are $\mathrm{Ni}$-based, 3 are Co-based systems, and 1 is Fe-based.

The magnitude of $\Delta H_{f}$ is closely associated with the high temperature limit of an alloy. If a compound has a large negative formation enthalpy, it is more likely to withstand decomposition at higher temperatures. Fig. 4 shows that many Ni-based alloys are as low as $-400 \mathrm{meV}$ compared to -167 $\mathrm{meV}$ of the discovered $\mathrm{Co}_{3}(\mathrm{Al}, \mathrm{W})$ superalloy [22].

Although the elemental form of $\mathrm{Fe}$ is bcc, fcc stabilizers (e.g., carbon, tungsten, or nickel) can be added in small amounts to stabilize the fcc structure. We have modeled Fe-based systems with $\mathrm{L}_{2}$ precipitate-forming potential by calculating fcc Fe, without explicitly including the effects of the stabilizing additions. Had we found promising Fe systems, this rough approximation would have needed refinement, but all of our promising candidates but one turned out to be Co- or Ni-based.

\subsection{Formation enthalpy and decomposition energy maps}

Recognizing that ternary $\mathrm{L} 1_{2}$ phases in known superalloys have large negative formation enthalpies and small decomposition energies, it is useful to identify chemical trends (via the Pettifor chemical scale) for these two quantities. We visualize these trends with Pettifor-like "formation enthalpy maps" and "decomposition energy maps" (Figs. 5 and 6). In the formation enthalpy maps, the formation enthalpy of every system computed in this work is displayed together, arranged in a grid ordered by the Pettifor scale [44] of the two minority components, $A, B$ in $X_{3}\left[A_{0.5}, B_{0.5}\right]$. In a similar Pettifor scale grid fashion, the decomposition energy maps show the decomposition energy of every system computed in this work (Fig. 5). The "islands" of similarly colored compounds visible in these plots reveal distinct chemical trends. Many of the promising superalloy candidates identified in our study with no previously reported phase diagrams are found within these islands. In general, early $d$-block elements and $p$-block combinations dominate the list of favorable systems, which have both low formation enthalpies and low decomposition energies. For Ni-based alloys, favorable compounds mostly comprise of transition metals Y, Sc, $\mathrm{Zr}, \mathrm{Hf}, \mathrm{Ti}, \mathrm{Nb}$, Ta, and metalloids, including Ga, $\mathrm{Si}$, and $\mathrm{Sb}$. In the case of Co-based alloys, combinations of $\mathrm{Zr}, \mathrm{Hf}, \mathrm{Ti}, \mathrm{Nb}$, $\mathrm{Ta}$, and $\mathrm{Al}$ define the majority of favorable compounds. Combinations of $\mathrm{Al}, \mathrm{Si}, \mathrm{Hf}$, and $\mathrm{Ti}$ with Fe tend to produce some favorable compounds as well. On the other hand, combinations with $\mathrm{Os}, \mathrm{Ru}$, and $\mathrm{Cr}$ tend to yield unstable compounds for combinations with $\mathrm{Ni}, \mathrm{Co}$, and Fe.

\subsection{Phase diagrams}

Ternary phase diagrams at $T=0 \mathrm{~K}$ for all 2111 compound-forming systems have been plotted in this work using the data in the open-access materials properties database Aflow [45]. Convex hulls constructed from a DFT database are only as reliable as the database is complete. To be robust, the database must include all possible structural prototypes. Our prototypes list includes essentially all known prototypes from the Pauling File [5, 24] (a database of experimentally observed binary metallic phases) and binary and ternary intermetallic prototypes $^{3}$ in the ICSD [46, 47]. Our prototypes list also includes binary and ternary hypothetical structures (enumerated as in Refs. [48, 49]). Our convex hulls were constructed from more than 800 DFT calculations per system. In total, 271,000 calculations were used for the 2111 compound-forming systems, giving us a high degree of the confidence that the phase stability predictions and potential superalloy candidates listed in this work are reasonably likely to be stable experimentally. Further evidence of the robustness of the calculations is given in Table 1.

The ternary phase diagrams of all 2111 compound-forming systems are included in the Supplementary Material accompanying this work and are available online via http://aflow.org/superalloys. They were created with the phase diagram module within AfLow. In almost all cases, the AFLOW convex hulls contain more phases than reported in the experimental databases. In some cases, this may indicate an

\footnotetext{
${ }^{3}$ Although entries with incomplete structural information or phases with partially occupied wyckoff positions obviously cannot be included.
} 


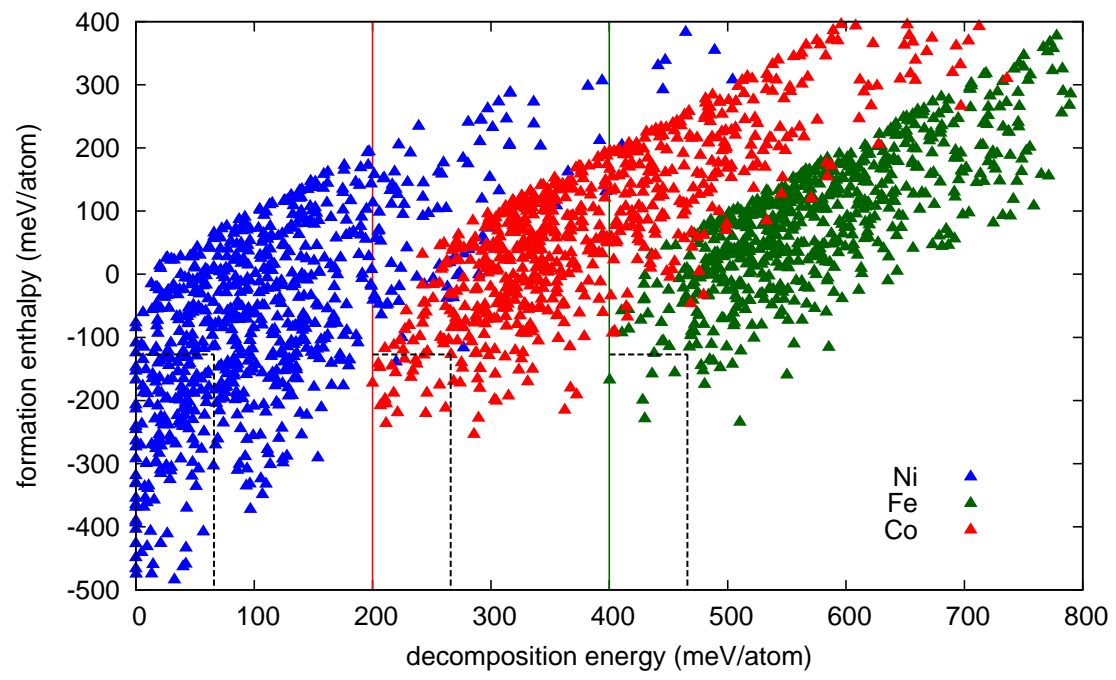

Figure 4: Formation enthalpy vs. the decomposition energy for all 2224 ternary systems. Each triangle represents one $\mathrm{Ni}_{3} / \mathrm{Co}_{3} / \mathrm{Fe}_{3}\left[A_{0.5}, B_{0.5}\right]$ structure, where $A$ and $B$ are any two different elements in the periodic table from Fig. 1 . Co-based and Fe-based systems are displaced on the $x$-axis by $200 \mathrm{meV}$ and $400 \mathrm{meV}$, respectively, for clarity. Ni-based, Co-based, and Fe-based systems are marked in blue, red, and green triangles, respectively. Systems enclosed within dotted lines are the ones identified to be better than the $\mathrm{Co}_{3}\left[\mathrm{Al}_{0.5}, \mathrm{~W}_{0.5}\right]$ structure with respect to these properties.

Table 1: Systems where the SQS structure computed in this work has a corresponding $\mathrm{L}_{2}$ phase reported in experiment. The experimental compounds are all close to the stoichiometry of the SQS structure, $X_{24}\left[A_{4}, B_{4}\right]$.

\begin{tabular}{ll}
\hline $\mathrm{SQS}$ & Exp. \\
\hline $\mathrm{Al}_{0.5} \mathrm{Cr}_{0.5} \mathrm{Ni}_{3}$ & $\mathrm{Al}_{0.8} \mathrm{Cr}_{0.2} \mathrm{Ni}_{3}[50]$ \\
$\mathrm{Al}_{0.5} \mathrm{Cu}_{0.5} \mathrm{Ni}_{3}$ & $\mathrm{Al}_{1} \mathrm{Cu}_{0.28} \mathrm{Ni}_{2.72}[51]$ \\
$\mathrm{Al}_{0.5} \mathrm{Ga}_{0.5} \mathrm{Ni}_{3}$ & $\mathrm{Al}_{0.5} \mathrm{Ga}_{0.5} \mathrm{Ni}_{3}[52]$ \\
$\mathrm{Al}_{0.5} \mathrm{Hi}_{0.5} \mathrm{Ni}_{3}$ & $\mathrm{Al}_{0.99} \mathrm{Hi}_{0.01} \mathrm{Ni}_{3}[53]$ \\
$\mathrm{Al}_{0.5} \mathrm{Nb}_{0.5} \mathrm{Ni}_{3}$ & $\mathrm{Al}_{0.65} \mathrm{Nb}_{0.35} \mathrm{Ni}_{3}[54]$ \\
$\mathrm{Al}_{0.5} \mathrm{Ni}_{3} \mathrm{Pt}_{0.5}$ & $\mathrm{Al}_{1} \mathrm{Ni}_{2.48} \mathrm{Pt}_{0.52}[51]$ \\
$\mathrm{Al}_{0.5} \mathrm{Ni}_{3} \mathrm{Si}_{0.5}$ & $\mathrm{Al}_{0.6} \mathrm{Ni}_{3} \mathrm{Si}_{0.4}[51]$ \\
$\mathrm{Al}_{0.5} \mathrm{Ni}_{3} \mathrm{Sn}_{0.5}$ & $\mathrm{Al}_{0.8} \mathrm{Ni}_{3} \mathrm{Sn}_{0.2}[50]$ \\
$\mathrm{Al}_{0.5} \mathrm{Ni}_{3} \mathrm{Ta}_{0.5}$ & $\mathrm{Al}_{0.76} \mathrm{Ni}_{3} \mathrm{Ta}_{0.24}[41]$ \\
$\mathrm{Al}_{0.5} \mathrm{Ni}_{3} \mathrm{Ti}_{0.5}$ & $\mathrm{Al}_{1} \mathrm{Ni}_{2.8} \mathrm{Ti}_{0.2}[40]$ \\
$\mathrm{Al}_{0.5} \mathrm{Ni}_{3} \mathrm{~V}_{0.5}$ & $\mathrm{Al}_{0.28} \mathrm{Ni}_{3} \mathrm{~V}_{0.2}[50]$ \\
$\mathrm{Co}_{3} \mathrm{Ti}_{0.5} \mathrm{~V}_{0.5}$ & $\mathrm{Co}_{3} \mathrm{Ti}_{0.87} \mathrm{~V}_{0.13}[57]$ \\
$\mathrm{Ga}_{0.5} \mathrm{Hf}_{4} \mathrm{Ni}_{3}$ & $\mathrm{Ga}_{0.88} \mathrm{Hf}_{0.12} \mathrm{Ni}_{3}[51]$ \\
$\mathrm{Ga}_{0.5} \mathrm{Nb}_{4} \mathrm{Ni}_{3}$ & $\mathrm{Ga}_{0.84} \mathrm{Nb}_{0.16} \mathrm{Ni}_{3}[51]$ \\
$\mathrm{Ga}_{0.5} \mathrm{Ni}_{3} \mathrm{Sb}_{0.5}$ & $\mathrm{Ga}_{0.92} \mathrm{Ni}_{3} \mathrm{Sb}_{0.08}[51]$ \\
$\mathrm{Ga}_{0.5} \mathrm{Ni}_{3} \mathrm{Si}_{0.5}$ & $\mathrm{Ga}_{0.4} \mathrm{Ni}_{3} \mathrm{Si}_{0.6}[51]$ \\
$\mathrm{Ga}_{0.5} \mathrm{Ni}_{3} \mathrm{Sn}_{0.5}$ & $\mathrm{Ga}_{0.84} \mathrm{Ni}_{3} \mathrm{Sn}_{0.16}[51]$ \\
$\mathrm{Ga}_{0.5} \mathrm{Ni}_{3} \mathrm{Ta}_{0.5}$ & $\mathrm{Ga}_{0.68} \mathrm{Ni}_{3} \mathrm{Ta}_{0.32}[51]$ \\
$\mathrm{Ga}_{0.5} \mathrm{Ni}_{3} \mathrm{Ti}_{0.5}$ & $\mathrm{Ga}_{0.84} \mathrm{Ni}_{3} \mathrm{Ti}_{0.16}[51]$ \\
$\mathrm{Ga}_{0.5} \mathrm{Ni}_{3} \mathrm{~V}_{0.5}$ & $\mathrm{Ga}_{0.76} \mathrm{Ni}_{3} \mathrm{~V}_{0.24}[51]$ \\
\hline \hline
\end{tabular}

opportunity for further experimental study, but it is likely that some of these DFT ground states are low temperature phases and are therefore kinetically inaccessible, which explains why they are not reported in experimental phase diagrams.

There are 66 systems which meet all our criteria discussed in Secs. 2.2 and 2.3 and for which there are published phase diagrams. In 20 of those systems, the predicted $\mathrm{L} 1_{2}$ phase is validated by an experimentally reported $\mathrm{L}_{2}$ phase at nearby concentrations. In 37 cases, the phase diagrams are incompete in the region of interest. In the remaining eight cases, three have fcc solid solutions near our composition, three report disordered $\chi$-like phases or unknown structures, one has a disordered $\mathrm{D}_{24}$ structure (closely related to $\mathrm{L}_{2}$ and a precipitate phase in some superalloys), and one reports the structure prototype $\mathrm{Mg}_{6} \mathrm{Cu}_{16} \mathrm{Si}_{7}$.

\subsection{Density of superalloys}

Low density and high-temperature strength are two critical properties of superalloys for any application. For example, increased density can result in higher stress on mating components in aircraft gas turbines [21]. A comparison between the density range for theoretical calculations performed in this work and modern superalloys is listed in Fig. 7. Of the theoretical ternary combinations, 
Figure 5: All the elements are arranged as per the chemical scale $(\chi)$ introduced by Pettifor [44] in increasing order. Each diamond, square, and circle represents a ternary combination $X_{3}\left[A_{0.5}, B_{0.5}\right]$ with $X=\mathrm{Ni}$, Co, or Fe, and $A, B$ specifying the elements indicated along the $x$ and $y$-axes, respectively. A square indicates that the SQS-32 crystal structure has a positive formation enthalpy. A diamond indicates that there exists no stable binary or ternary compounds in the respective ternary system. A colored circle indicates that the SQS-32 structure has a negative formation enthalpy. The color contrast from yellow to black indicates decreasing formation enthalpy of the crystal structure in the ternary system. 
Figure 6: All the elements are arranged as per the chemical scale $(\chi)$ introduced by Pettifor [44] in increasing order. Each diamond, square, and circle represents a ternary combination $X_{3}\left[A_{0.5}, B_{0.5}\right]$ with $X=\mathrm{Ni}$, Co, or Fe, and $A, B$ are the elements indicated along the $x$ and $y$-axes, respectively. A square indicates that the SQS-32 crystal structure has a positive formation enthalpy. A diamond indicates that there exists no stable binary or ternary compounds in the respective ternary system. The color contrast of the circles from yellow to black indicates increasing decomposition energy of the crystal structure in the ternary system.

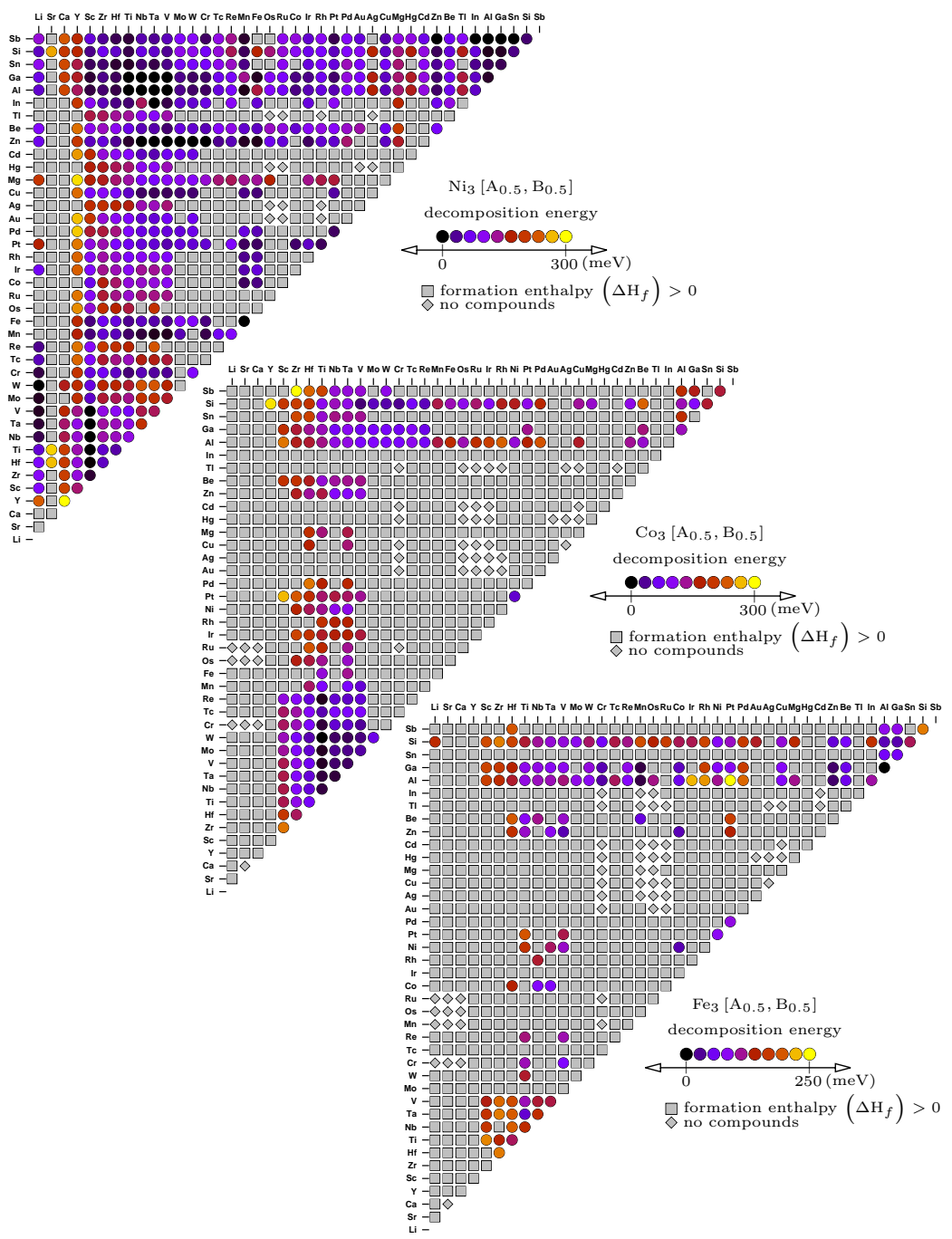




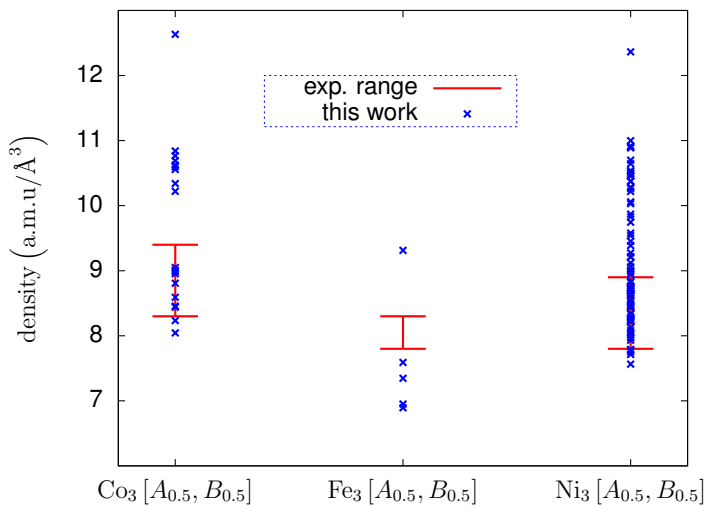

Figure 7: A comparison between the density range for the theoretical calculations performed in this work and modern superalloys. Densities are computed for 102 ternary systems screened from the 2224 systems computed in this work. The red line shows the range of density for commercially-available superalloys at present.

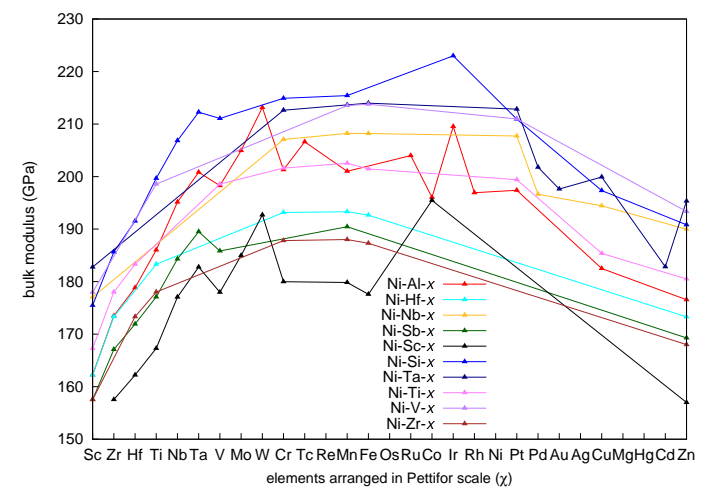

Figure 8: The magnitude of the bulk modulus for $\mathrm{Ni}-A-x$ ( $A$ $=\mathrm{Al}, \mathrm{Hf}, \mathrm{Nb}, \mathrm{Sb}, \mathrm{Sc}, \mathrm{Si}, \mathrm{Ta}, \mathrm{Ti}, \mathrm{V}$, and $\mathrm{Zr}$ ) systems with the $x$-axis arranged according to the $\chi$ scale in Pettifor maps. In general, the systems display a maximum in the bulk modulus at or before Ni. Only systems with simultaneously lower $E_{d}$ and $\Delta H_{f}$ than $\mathrm{Co}_{3}\left[\mathrm{Al}_{0.5}, \mathrm{~W}_{0.5}\right]$ are plotted.

there are 5 Ni-based alloys 2 Co-based and 4 Febased alloys with density less than the range of commercially-available superalloys. This certainly warrants further analysis of mechanical properties of these alloys, which may yield novel lightweight, high-strength superalloys.

\subsection{Bulk modulus}

For the aforementioned systems with simultaneously lower $E_{d}$ and $\Delta H_{f}$ than the $\mathrm{Co}_{3}(\mathrm{Al}, \mathrm{W})$ system, the bulk modulus is computed in this work. All the Co- and Fe-based alloys have a bulk modulus of at least $200 \mathrm{GPa}$. This is consistent with the observation that commercial Co-based alloys have better mechanical properties than many $\mathrm{Ni}$-based alloys [1].

Figs. 8 and 9 depict the magnitude of the bulk modulus for Ni- $A-x(A=\mathrm{Al}, \mathrm{Hf}, \mathrm{Nb}, \mathrm{Sb}, \mathrm{Sc}, \mathrm{Si}, \mathrm{Ta}$, $\mathrm{Ti}, \mathrm{V}$, and $\mathrm{Zr})$ and $\mathrm{Co}-A-x(A=\mathrm{Hf}, \mathrm{Mo}, \mathrm{Nb}, \mathrm{Si}, \mathrm{Ta}$, $\mathrm{Ti}, \mathrm{V}$, and $\mathrm{W}$ ) systems. $x$ is the third element in the ternary system and arranged along the $x$-axis of the plot in increasing order of the Pettifor chemical scale $(\chi)$. The bulk modulus of ternary alloys of the form $\mathrm{Ni}-A-x$ reaches a maximum at or before Ni. In case of Co- $A-x$ systems, the bulk modulus increases with increasing $\chi$ up to Re.

The magnitude of the bulk modulus suggests that Co-based superalloys are particularly resistant to compression compared to Ni-based superalloys. 68 ternary systems with simultaneously lower $E_{d}$ and $\Delta H_{f}$ than $\mathrm{Co}_{3}\left[\mathrm{Al}_{0.5}, \mathrm{~W}_{0.5}\right]$ have bulk moduli greater than $200 \mathrm{GPa}$.

\subsection{Promising Candidates}

Table 2 lists the 37 systems that are predicted to have stable precipitate-forming $\mathrm{L}_{2}$ phases and for which there are no reported phase diagrams in standard databases $[4,24,5]$. Avoiding elements (i.e., $\mathrm{Au}, \mathrm{Be}, \mathrm{Cd}, \mathrm{Ga}, \mathrm{Hg}$, Ir, In, Li, Os, Pd, Pt, Re, Rh, $\mathrm{Ru}, \mathrm{Sb}, \mathrm{Sc}, \mathrm{Tc}$, and $\mathrm{Tl}$ ), that are toxic, expensive, or have low melting temperatures (which can result in difficulty incorporating them in alloy synthesis), we prioritize this list into a smaller set of six candidate superalloy systems. These are denoted by boxes in Table 2.

\section{Conclusion}

We used DFT calculations to search for new ternary systems with $\mathrm{L}_{2}$ precipitate-forming potential. We examined a total of 2224 different ternary systems comprising 41 different elements. The Pettifor-type formation enthalpy and decomposition energy maps (Fig. 5 and 6) introduced in this work reveal that combinations of early $d$-block and $p$-block elements tend to form stable superalloy systems with base-elements $\mathrm{Ni}, \mathrm{Co}$, and Fe. 
Table 2: Candidates for precipitate-forming systems that have no previously reported phase diagrams in standard databases [5, $24,46,47]$. These have a smaller decomposition energy and a lower formation enthalpy than the $\mathrm{Co}_{3}(\mathrm{Al}, \mathrm{W})$ superalloy. All are in stable two-phase equilibrium with the host matrix and have a relative lattice mismatch with the host matrix of less than or equal to 5\%. Promising candidates (see section 3.6) are boxed. ' $* * *$ ' indicates that the quantity is not computed in this work.

\begin{tabular}{|c|c|c|c|c|c|}
\hline System & $\begin{array}{l}\text { Formation } \\
\text { enthalpy } \\
{[\mathrm{meV}]}\end{array}$ & $\begin{array}{l}\text { Decomposition } \\
\text { energy } \\
{[\mathrm{meV} / \text { atom] }}\end{array}$ & $\begin{array}{l}\text { Density } \\
{\left[\mathrm{gm} / \mathrm{cm}^{3}\right]}\end{array}$ & $\begin{array}{l}\text { Bulk } \\
\text { modulus } \\
{[\mathrm{GPa}]}\end{array}$ & $\begin{array}{l}\text { Relative lattice } \\
\text { mismatch } \\
{[\%]}\end{array}$ \\
\hline $\mathrm{Al}_{4} \mathrm{Ni}_{24} \mathrm{Rh}_{4}$ & -189 & 49 & 8.71 & 197 & -2 \\
\hline $\mathrm{Au}_{4} \mathrm{Ni}_{24} \mathrm{Ta}_{4}$ & -142 & 46 & 12.17 & 198 & -5 \\
\hline $\mathrm{Be}_{4} \mathrm{Fe}_{4} \mathrm{Ni}_{24}$ & -129 & 40 & 8.20 & 206 & 1 \\
\hline $\mathrm{Be}_{4} \mathrm{Ga}_{4} \mathrm{Ni}_{24}$ & -203 & 59 & 8.33 & 184 & 0 \\
\hline $\mathrm{Be}_{4} \mathrm{Mn}_{4} \mathrm{Ni}_{24}$ & -132 & 43 & 8.12 & $* * *$ & 1 \\
\hline $\mathrm{Be}_{4} \mathrm{Nb}_{4} \mathrm{Ni}_{24}$ & -237 & 37 & 8.38 & 198 & -1 \\
\hline $\mathrm{Be}_{4} \mathrm{Ni}_{24} \mathrm{Sb}_{4}$ & -159 & 59 & 8.71 & 177 & -2 \\
\hline $\mathrm{Be}_{4} \mathrm{Ni}_{24} \mathrm{Si}_{4}$ & -298 & 48 & 7.78 & 201 & 1 \\
\hline $\mathrm{Be}_{4} \mathrm{Ni}_{24} \mathrm{Ta}_{4}$ & -269 & 33 & 10.02 & 204 & -1 \\
\hline $\mathrm{Be}_{4} \mathrm{Ni}_{24} \mathrm{Ti}_{4}$ & -308 & 53 & 7.79 & 189 & 0 \\
\hline $\mathrm{Be}_{4} \mathrm{Ni}_{24} \mathrm{~V}_{4}$ & -225 & 21 & 8.07 & 203 & 1 \\
\hline $\mathrm{Be}_{4} \mathrm{Ni}_{24} \mathrm{~W}_{4}$ & -144 & 44 & 10.23 & 219 & -1 \\
\hline $\mathrm{Co}_{24} \mathrm{Nb}_{4} \mathrm{~V}_{4}$ & -156 & 19 & 9.05 & 238 & -2 \\
\hline $\mathrm{Co}_{4} \mathrm{Ni}_{24} \mathrm{Sc}_{4}$ & -166 & 55 & 8.04 & 169 & -3 \\
\hline $\mathrm{Co}_{24} \mathrm{Re}_{4} \mathrm{Ti}_{4}$ & -142 & 5 & 10.69 & 253 & -2 \\
\hline $\mathrm{Co}_{24} \mathrm{Ta}_{4} \mathrm{~V}_{4}$ & -189 & 18 & 10.62 & 243 & -2 \\
\hline $\mathrm{Fe}_{24} \mathrm{Ga}_{4} \mathrm{Si}_{4}$ & -200 & 28 & 7.59 & $* * *$ & -4 \\
\hline $\mathrm{Ga}_{4} \mathrm{Ir}_{4} \mathrm{Ni}_{24}$ & -129 & 27 & 11.00 & 209 & -2 \\
\hline $\mathrm{Hf}_{4} \mathrm{Ni}_{24} \mathrm{Si}_{4}$ & -459 & 42 & 9.83 & 192 & -3 \\
\hline $\mathrm{In}_{4} \mathrm{Ni}_{24} \mathrm{~V}_{4}$ & -165 & 14 & 8.91 & 182 & -4 \\
\hline $\mathrm{Ir}_{4} \mathrm{Ni}_{24} \mathrm{Si}_{4}$ & -184 & 55 & 10.54 & 223 & -1 \\
\hline $\mathrm{Mn}_{4} \mathrm{Ni}_{24} \mathrm{Sb}_{4}$ & -151 & 8 & 9.06 & 184 & -4 \\
\hline $\mathrm{Nb}_{4} \mathrm{Ni}_{24} \mathrm{Pd}_{4}$ & -129 & 52 & 9.39 & 197 & -4 \\
\hline $\mathrm{Nb}_{4} \mathrm{Ni}_{24} \mathrm{Pt}_{4}$ & -172 & 48 & 10.89 & 208 & -4 \\
\hline $\mathrm{Nb}_{4} \mathrm{Ni}_{24} \mathrm{Zn}_{4}$ & -241 & 0 & 8.95 & 190 & -3 \\
\hline $\mathrm{Ni}_{24} \mathrm{Pd}_{4} \mathrm{Ta}_{4}$ & -160 & 51 & 10.92 & 202 & -4 \\
\hline $\mathrm{Ni}_{24} \mathrm{Pt}_{4} \mathrm{Si}_{4}$ & -228 & 39 & 10.46 & 211 & -2 \\
\hline $\mathrm{Ni}_{24} \mathrm{Pt}_{4} \mathrm{Ta}_{4}$ & -202 & 45 & 12.36 & 213 & -4 \\
\hline $\mathrm{Ni}_{24} \mathrm{Pt}_{4} \mathrm{Ti}_{4}$ & -250 & 58 & 10.38 & 199 & -3 \\
\hline $\mathrm{Ni}_{24} \mathrm{Sb}_{4} \mathrm{Si}_{4}$ & -310 & 21 & 8.82 & 187 & -3 \\
\hline $\mathrm{Ni}_{24} \mathrm{Sb}_{4} \mathrm{Ti}_{4}$ & -335 & 11 & 8.72 & 177 & -5 \\
\hline $\mathrm{Ni}_{24} \mathrm{Sc}_{4} \mathrm{Zn}_{4}$ & -241 & 39 & 7.97 & 157 & -4 \\
\hline $\mathrm{Ni}_{24} \mathrm{Si}_{4} \mathrm{Sn}_{4}$ & -303 & 26 & 8.76 & 185 & -3 \\
\hline $\mathrm{Ni}_{24} \mathrm{Ta}_{4} \mathrm{Zn}_{4}$ & -274 & 0 & 10.49 & 195 & -3 \\
\hline $\mathrm{Ni}_{24} \mathrm{~V}_{4} \mathrm{Zn}_{4}$ & -213 & 0 & 8.66 & 193 & -1 \\
\hline $\mathrm{Ni}_{24} \mathrm{~W}_{4} \mathrm{Zn}_{4}$ & -147 & 0 & 10.70 & 210 & -2 \\
\hline $\mathrm{Ni}_{24} \mathrm{Zn}_{4} \mathrm{Zr}_{4}$ & -261 & 48 & 8.61 & 168 & -4 \\
\hline
\end{tabular}




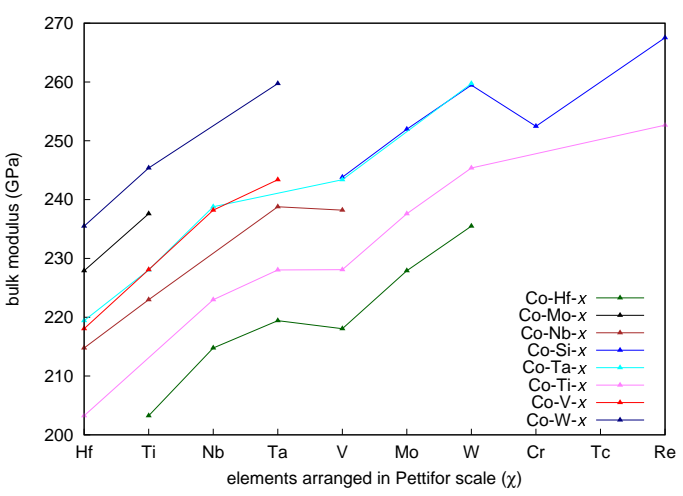

Figure 9: The magnitude of the bulk modulus for Co- $A-x$ $(A=\mathrm{Hf}, \mathrm{Mo}, \mathrm{Nb}, \mathrm{Si}, \mathrm{Ta}, \mathrm{Ti}, \mathrm{V}$, and $\mathrm{W})$ systems with the $x$-axis arranged according to the $\chi$ scale in Pettifor maps. In general, the magnitude of the bulk modulus increases with $\chi$ up to Re. Only systems with simultaneously lower $E_{d}$ and $\Delta H_{f}$ than $\mathrm{Co}_{3}\left[\mathrm{Al}_{0.5}, \mathrm{~W}_{0.5}\right]$ are plotted.

Ni-based superalloys tend to be thermodynamically more stable than Co- or Fe-based superalloys.

A total of 102 ternary systems are found to have lower formation enthalpy and decomposition energy than the recently discovered $\mathrm{Co}_{3}\left[\mathrm{Al}_{0.5}, \mathrm{~W}_{0.5}\right]$ superalloy. All the systems are observed to be in two-phase equilibrium with the host matrix and have a lattice mismatch of less than or equal to $5 \%$ with the host matrix. Further analysis should be done for these systems with, e.g., cluster expansion $[64,65,66]$ in the interest of experimental verification. Of these, 37 systems have no experimental phase diagram reported in literature. A comparison between the density range for our theoretical systems and modern superalloys reveal many candidate low-density superalloys. Co-based superalloys are observed to have a higher bulk modulus than $\mathrm{Ni}$ - and Fe-based alloys. Based on cost, experimental difficulty, and toxicity, we prioritize a shorter list of six promising superalloy systems (see Table 2).

\section{Acknowledgments}

The authors thank Eric Perim, Eric Gossett, M. Buongiorno Nardelli, M. Fornari, S. Butenko, and $\mathrm{C}$. Toher for useful discussion. Funding from ONR (MURI N00014-13-1-0635). C. Oses acknowledges support from the National Science Foundation Graduate Research Fellowship under Grant
No. DGF1106401. Calculations were performed at the Duke University Center for Materials Genomics and at the BYU Fulton Supercomputing Lab.

\section{Appendix A. Phase Diagram (Convex Hull) Analysis}

We construct the $T=0 \mathrm{~K}$ convex hull using the phase diagram module within AfLOw [7]. Elements of this implementation were inspired by the QHULL algorithm [67]. For $k$-nary systems, it computes the distances to the hull with the following considerations. Let a facet of the convex hull, i.e., a hyperplane, be described by,

$$
a_{0}+\sum_{m=1}^{k} a_{m} x_{m}=0 .
$$

Here $a_{1}, \ldots, a_{k}$ define the normals of the hyperplane while the constant $a_{0}$ uniquely defines the hyperplane in space. This is a simple extension of the familiar 3-D plane equation $A x+B y+C z=D$. Let a $k$-nary structure have the coordinates denoted in $k$-dimensional space as $c_{1}, c_{2}, \ldots, c_{k}$, where $c_{1}, \ldots, c_{k-1}$, are the concentrations of the $k-1$ elements in a $k$-nary system and $c_{k}$ is the formation enthalpy. Note that we neglect the concentration of the $k^{t h}$ element because it is implicit given the other $k-1$ concentrations. The distance $d$ of the structure to a given facet of the convex hull is computed as follows,

$$
d=c_{n}-\left(1 / a_{n}\right)\left(-a_{0}+\sum_{m=1}^{n-1} a_{m} c_{m}\right) .
$$

This equation is different from the nominal (shortest) distance between a plane and a point, which projects the point onto the plane along the normal vector. Instead, we want the distance that projects the point onto the plane along the energy axis.

The distance of the structure to the convex hull is the minimum of Eq. A.2 computed for all facets of the convex hull. This minimization avoids a costly analysis of identifying the relevant facet, including the conversion of all facet vertices to barycentric coordinates. However, it is important to recognize that this minimization algorithm is only valid for compounds above the convex hull.

The correct (incorrect) distances of each structure to the convex hull is illustrated by the green (red) lines in Fig. A.10a. For structures within the 


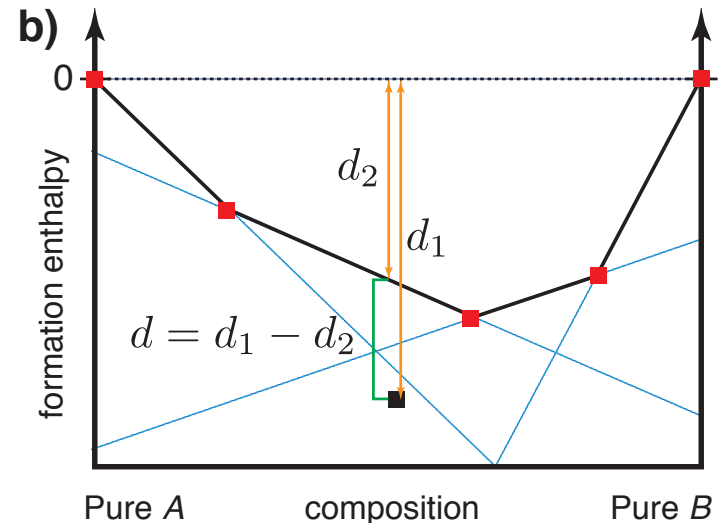

Figure A.10: Distance to the $T=0 \mathrm{~K}$ convex hull algorithm. a) The correct distance (shown in green) for $d_{1}$ is the minimum distance of structure $S_{1}$ to all hyperplanes defining the convex hull. In case of structure $S_{2}$, the minimum distance is not $d_{2}$ (green line), an artifact of the hyperplane description for hull facets. b) Projecting the points to the zero energy line guarantees that all points will lie within the hull, thus enabling the use of minimization algorithm to calculate the correct distance. The distance to the hull $d$ is given as the difference of the projected distance $d_{2}$ from the distance to the zero energy line $d_{1}$.

convex hull, i.e., $S_{1}$, the minimum distance correctly matches the structure to the plane immediately below it. However, imagine we were interested in determining the importance/stability of a convex hull member. This property may be quantified by determining the distance of this structure from the bottom of a new pseudo-hull which does not contain the structure, such as what is illustrated by $S_{2}$. For such cases, we need a generalized distance to hull algorithm. The minimization algorithm alone would not identify the correct facet because the algorithm is dependent on the hyperplane description of the facet. Therefore, it is possible to find the imaginary extension of a distant facet to be closer to the compound than that of the correct facet. To avoid this problem, we generalize our algorithm by simply taking the projection of the point (compound) to the zero energy line, perform the minimization, and subtract the projected distance. This is illustrated in Fig. A.10b. 
structural and electronic fingerprints, Chem. Mater. 27 (2015) 735-743.

[1] J. Sato, T. Omori, K. Oikawa, I. Ohnuma, R. Kainuma, K. Ishida, Cobalt-base high-temperature alloys, Science 312 (2006) 90-91.

[2] MatWeb, LLC, Matweb material property data: http://www.matweb.com, 2011.

[3] Matbase: http://www.matbase.com, 2003.

[4] P. Villars, H. Okamoto, K. Cenzual, ASM alloy phase diagram database: http://www1.asminternational.org/AsmEnterprise/APD, 2006.

[5] P. Villars, M. Berndt, K. Brandenburg, K. Cenzual, J. Daams, F. Hulliger, T. Massalski, H. Okamoto, K. Osaki, A. Prince, H. Putz, and S. Iwata, The Pauling file, binaries edition, J. Alloys Compound. 367 (2004) 293-297.

[6] S. Curtarolo, G. L. W. Hart, M. Buongiorno Nardelli, N. Mingo, S. Sanvito, O. Levy, The high-throughput highway to computational materials design, Nat. Mater. 12 (2013) 191-201.

[7] S. Curtarolo, W. Setyawan, G. L. W. Hart, M. Jahnátek, R. V. Chepulskii, R. H. Taylor, S. Wang, J. Xue, K. Yang, O. Levy, M. J. Mehl, H. T. Stokes, D. O. Demchenko, D. Morgan, AFLOW: An automatic framework for high-throughput materials discovery, Comp. Mat. Sci. 58 (2012) 218-226.

[8] S. Curtarolo, W. Setyawan, S. Wang, J. Xue, K. Yang, R. H. Taylor, L. J. Nelson, G. L. W. Hart, S. Sanvito, M. Buongiorno Nardelli, N. Mingo, O. Levy, AFLOWLIB.ORG: A distributed materials properties repository from high-throughput $a b$ initio calculations, Comp. Mat. Sci. 58 (2012) 227-235.

[9] A. Jain, S. P. Ong, G. Hautier, W. Chen, W. D. Richards, S. Dacek, S. Cholia, D. Gunter, D. Skinner, G. Ceder, K. A. Persson, Commentary: The Materials Project: A materials genome approach to accelerating materials innovation, APL Mater. 1 (2013) 011002.

[10] J. Hachmann, R. Olivares-Amaya, S. Atahan-Evrenk, C. Amador-Bedolla, R. S. Sánchez-Carrera, A. GoldParker, L. Vogt, A. M. Brockway, A. Aspuru-Guzik, The Harvard Clean Energy Project: Large-scale computational screening and design of organic photovoltaics on the world community grid, J. Phys. Chem. Lett. 2 (2011) 2241-2251.

[11] M. Scheffler, C. Draxl, Computer Center of the MaxPlanck Society, Garching, The NoMaD repository: http://nomad-repository.eu, 2014.

[12] O. Levy, G. L. W. Hart, S. Curtarolo, Uncovering compounds by synergy of cluster expansion and highthroughput methods, J. Am. Chem. Soc. 132 (2010) 4830-4833.

[13] L.-F. Arsenault, O. A. von Lilienfeld, A. J. Millis, Machine learning for many-body physics: efficient solution of dynamical mean-field theory, arXiv:1506.08858 (2015).

[14] K. Hansen, F. Biegler, R. Ramakrishnan, W. Pronobis, O. A. von Lilienfeld, K.-R. Müller, A. Tkatchenko, Machine learning predictions of molecular properties: Accurate many-body potentials and nonlocality in chemical space, J. Phys. Chem. Lett. 6 (2015) 2326-2331.

[15] O. Isayev, D. Fourches, E. N. Muratov, C. Oses, K. Rasch, A. Tropsha, S. Curtarolo, Materials cartography: Representing and mining materials space using

[16] J. Carrete, N. Mingo, S. Wang, S. Curtarolo, Nanograined half-Heusler semiconductors as advanced thermoelectrics: An ab initio high-throughput statistical study, Adv. Func. Mater. 24 (2014) 7427-7432.

[17] L. M. Ghiringhelli, J. Vybiral, S. V. Levchenko, C. Draxl, M. Scheffler, Big data of materials science: Critical role of the descriptor, Phys. Rev. Lett. 114 (2015) 105503.

[18] O. Levy, M. Jahnátek, R. V. Chepulskii, G. L. W. Hart, S. Curtarolo, Ordered structures in rhenium binary alloys from first-principles calculations, J. Am. Chem. Soc. 133 (2011) 158-163.

[19] M. Jahnátek, O. Levy, G. L. W. Hart, L. J. Nelson, R. V. Chepulskii, J. Xue, S. Curtarolo, Ordered phases in ruthenium binary alloys from high-throughput firstprinciples calculations, Phys. Rev. B 84 (2011) 214110.

[20] O. Levy, G. L. W. Hart, S. Curtarolo, Structure maps for hcp metals from first-principles calculations, Phys. Rev. B 81 (2010) 174106.

[21] M. J. Donachie, S. J. Donachie, Superalloys: A Technical Guide, 2nd Edition, ASM International, 2002.

[22] J. E. Saal, C. Wolverton, Thermodynamic stability of Co-Al-W L1 $1_{2} \gamma^{\prime}$, Acta Mater. 61 (2013) 2330-2338.

[23] A. Zunger, S.-H. Wei, L. G. Ferreira, J. E. Bernard, Special quasirandom structures, Phys. Rev. Lett. 65 (1990) 353-356.

[24] P. Villars, K. Cenzual, J. L. C. Daams, F. Hulliger, T. B. Massalski, H. Okamoto, K. Osaki, A. Prince, S. Iwata, Crystal Impact, Pauling File. Inorganic Materials Database and Design System,Binaries Edition, ASM International, Metal Park, OH, 2003.

[25] C. Jiang, Y. Du, Thermodynamic and mechanical stabilities of $\gamma^{\prime}-\operatorname{Ir}_{3}(\mathrm{Al}, \mathrm{W})$, J. Appl. Phys. 109 (2011).

[26] C. E. Calderon, J. J. Plata, C. Toher, C. Oses, O. Levy, M. Fornari, A. Natan, M. J. Mehl, G. L. W. Hart, M. Buongiorno Nardelli, S. Curtarolo, The AFLOW standard for high-throughput materials science calculations, Comp. Mat. Sci. 108 Part A (2015) 233-238.

[27] R. H. Taylor, F. Rose, C. Toher, O. Levy, K. Yang, M. Buongiorno Nardelli, S. Curtarolo, A RESTful API for exchanging materials data in the AFLOWLIB.org consortium, Comp. Mat. Sci. 93 (2014) 178-192.

[28] G. Kresse, J. Hafner, Norm-conserving and ultrasoft pseudopotentials for first-row and transition-elements, J. Phys.: Conden. Matt. 6 (1994) 8245-8257.

[29] P. E. Blöchl, Projector augmented-wave method, Phys. Rev. B 50 (1994) 17953-17979.

[30] G. Kresse, D. Joubert, From ultrasoft pseudopotentials to the projector augmented-wave method, Phys. Rev. B 59 (1999) 1758.

[31] J. P. Perdew, K. Burke, M. Ernzerhof, Generalized gradient approximation made simple, Phys. Rev. Lett. 77 (1996) 3865-3868.

[32] J. P. Perdew, K. Burke, M. Ernzerhof, Erratum: Generalized gradient approximation made simple, Phys. Rev. Lett. 78 (1997) 1396.

[33] G. Kresse, J. Furthmüller, Efficiency of ab-initio total energy calculations for metals and semiconductors using a plane-wave basis set, Comp. Mat. Sci. 6 (1996) 15.

[34] G. Kresse, J. Furthmüller, Efficient iterative schemes for $a b$ initio total-energy calculations using a planewave basis set, Phys. Rev. B 54 (1996) 11169-11186.

[35] H. J. Monkhorst, J. D. Pack, Special points for 
Brillouin-zone integrations, Phys. Rev. B 13 (1976) 5188-5192.

[36] C. Jiang, First-principles study of ternary bcc alloys using special quasi-random structures, Acta Mater. 57 (2009) 4716-4726.

[37] S. Curtarolo, D. Morgan, G. Ceder, Accuracy of $a b$ initio methods in predicting the crystal structures of metals: A review of 80 binary alloys, Calphad 29 (2005) 163-211.

[38] G. L. W. Hart, S. Curtarolo, T. B. Massalski, O. Levy, Comprehensive search for new phases and compounds in binary alloy systems based on platinum-group metals, using a computational first-principles approach, Phys. Rev. X 3 (2013) 041035.

[39] R. H. Taylor, S. Curtarolo, G. L. W. Hart, Guiding the experimental discovery of magnesium alloys, Phys. Rev. B 84 (2011) 084101.

[40] B. Huneau, P. Rogl, K. Zeng, R. Schmid-Fetzer, M. Bohn, J. Bauer, The ternary system Al-Ni-Ti part I: Isothermal section at $900^{\circ} \mathrm{C}$; experimental investigation and thermodynamic calculation, Intermetallics 7 (1999) 1337-1345.

[41] B. C. Giessen, N. J. Grant, New intermediate phases in transition metal systems, III, Acta Cryst. 18 (1965) 1080-1081.

[42] S. Kirklin, J. E. Saal, V. I. Hegde, C. Wolverton, Highthroughput computational search for strengthening precipitates in alloys, Acta Mater. 102 (2016) 125-135.

[43] F. D. Murnaghan, The compressibility of media under extreme pressures, Proc. Natl. Acad. Sci. 30 (1944) 244-247.

[44] D. G. Pettifor, A chemical scale for crystal-structure maps, Sol. State Commun. 51 (1984) 31-34.

[45] W. Setyawan, S. Curtarolo, AflowLib: Abinitio Electronic Structure Library Database, http://www.aflowlib.org (2011).

[46] V. L. Karen, M. Hellenbrandt, Inorganic crystal structure database: new developments, Acta Cryst. A58 (2002) c367.

[47] I. D. Brown, S. C. Abrahams, M. Berndt, J. Faber, V. L. Karen, W. D. S. Motherwell, P. Villars, J. D. Westbrook, B. McMahon, Report of the working group on crystal phase identifiers, Acta Cryst. A61 (2005) $575-580$.

[48] G. L. W. Hart, R. W. Forcade, Generating derivative structures: Algorithm and applications, Phys. Rev. B 77 (2008) 224115.

[49] G. L. W. Hart, R. W. Forcade, Generating derivative structures from multilattices: Algorithm and application to hcp alloys, Phys. Rev. B 80 (2009) 014120.

[50] I. Ul-Haq, J. G. Booth, Magnetic and structural properties of $\mathrm{Ni}_{3} \mathrm{Al}$ based alloys, J. Magn. Magn. Mater. 62 (1986) 256-268.

[51] Y. Mishima, S. Ochiai, T. Suzuki, Lattice parameters of $\mathrm{Ni}(\gamma), \mathrm{Ni}_{3} \mathrm{Al}\left(\gamma^{\prime}\right)$ and $\mathrm{Ni}_{3} \mathrm{Ga}\left(\gamma^{\prime}\right)$ solid solutions with additions of transition and B-subgroup elements, Acta Matallurgica 33 (1985) 1161-1169.

[52] S. Ochiai, Y. Mishima, T. Suzuki, Lattice parameter data of nickel (gamma), ni sub 3 al (gamma prime) and ni sub 3 ga (gamma prime) solid solutions, Bull. Res. Lab. Precis. Mach. Electron. (1984) 15-28.

[53] P. Rao, K. S. Murthy, S. Suryanarayana, S. Naidu, Effect of ternary additions on the room temperature lattice parameter of ni3al, physica status solidi (a) 133 (1992) 231-235.
[54] R. S. Mints, G. F. Belyaeva, Y. S. Malkov, Equilibrium diagram of the $\mathrm{Ni}_{3} \mathrm{Al}-\mathrm{Ni}_{3} \mathrm{Nb}$ system, Russ. J. Inorg. Chem. 7 (1962) 1236-1239.

[55] E. Gladyshevskii, P. Kripyakevich, Y. B. Kuz'ma, The crystal structure of low-silicon ternary compounds in the cr- ni- si and cr- co- si systems, Journal of Structural Chemistry 3 (1962) 402-410.

[56] D. Bardos, P. Beck, Electron phases in certain ternary alloys of transition metals with silicon, AIME MET SOC TRANS 236 (1966) 64-69.

[57] Y. Liu, T. Takasugi, O. Izumi, Alloying behavior of co3ti, Metallurgical Transactions A 17 (1986) 14331439.

[58] E. Gladyshevskii, L. Borusevich, Troinaya sistema crni-si, ZHURNAL NEORGANICHESKOI KHIMII 8 (1963) 1915-1920.

[59] L. Pryakhina, A. Y. Snetkov, L. Ryabtsev, X-ray diffraction investigation of multicomponent ni solid solutions', Fiz. Met. Metalloved 11 (1961) 670-676.

[60] I. Cosma, E. Burzo, Les proprietes magnetiques des alliages ni0. 8 (cu1- $\chi$ si $\chi$ ) 0.2, Solid State Communications 10 (1972) 585-589.

[61] B. Hu, H. Xu, S. Liu, Y. Du, C. He, C. Sha, D. Zhao, Y. Peng, Experimental investigation and thermodynamic modeling of the mn-ni-si system, Calphad 35 (2011) 346-354.

[62] A. Grytsiv, J. J. Ding, P. Rogl, F. Weill, B. Chevalier, J. Etourneau, G. André, F. Bourée, H. Noël, P. Hundegger, et al., Crystal chemistry of the g-phases in the systems ti $-\{\mathrm{Fe}, \mathrm{Co}, \mathrm{Ni}\}-$ al with a novel filled variant of the th $6 \mathrm{mn}$ 23-type, Intermetallics 11 (2003) 351-359.

[63] V. Romaka, P. Rogl, L. Romaka, Y. Stadnyk, N. Melnychenko, A. Grytsiv, M. Falmbigl, N. Skryabina, Phase equilibria, formation, crystal and electronic structure of ternary compounds in ti-ni-sn and ti-ni-sb ternary systems, Journal of Solid State Chemistry 197 (2013) $103-112$.

[64] J. M. Sanchez, F. Ducastelle, D. Gratias, Generalized cluster description of multicomponent systems, Physica A 128 (1984) 334-350.

[65] D. de Fontaine, Cluster approach to order-disorder transformations in alloys, in: H. Ehrenreich, D. Turnbull (Eds.), Solid State Physics, volume 47, Wiley, New York, 1994, pp. 33-176.

[66] A. Zunger, First-principles statistical mechanics of semiconductor alloys and intermetallic compounds, in: A. Gonis, P. Turchi (Eds.), NATO Advanced Study Institute on Statics and Dynamics of Alloy Phase Transformations, 1994, pp. 361-419.

[67] C. B. Barber, D. P. Dobkin, H. Huhdanpaa, The quickhull algorithm for convex hulls, ACM Trans. Math. Soft. 22 (1996) 469-483. 


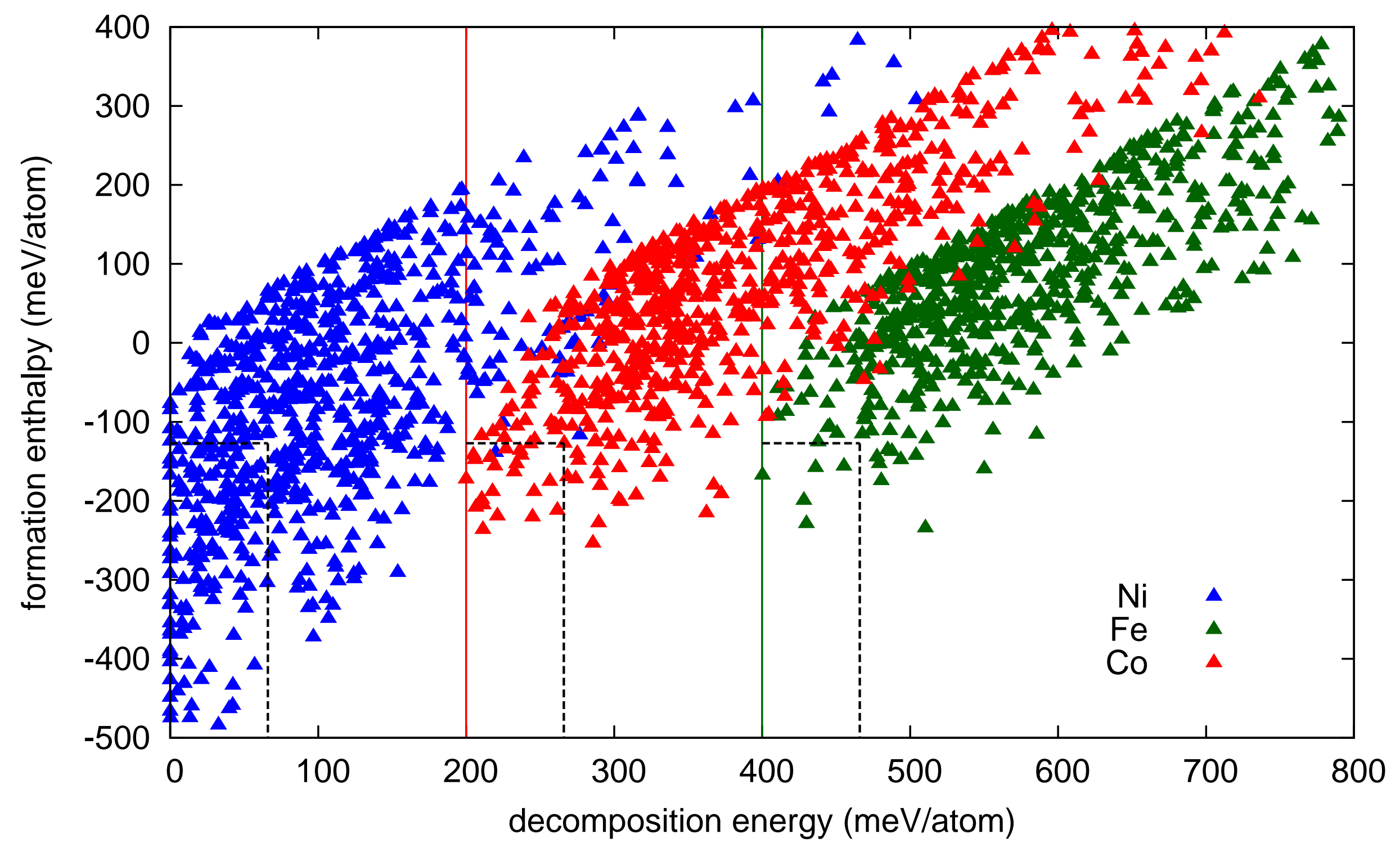

